\title{
Retroflexão e evisceração da vesícula urinária decorrente de ruptura dos órgãos genitais em cadela
}

\author{
Retroflexion and evisceration of the urinary bladder due to rupture of the genitals organs in bitch
}

\author{
Bruna Pinto Coutinho ${ }^{{ }^{*}}$ Érika Labat $^{\mathrm{I}}$ Antonio Soares Coutinho Junior ${ }^{\mathrm{II}}$ Murilo Cézar Curti ${ }^{\mathrm{I}}$ \\ Josmarí Pirolo ${ }^{\mathrm{III}}$ Milton Luis Ribeiro de Oliveira" ${ }^{\mathrm{III}}$ Mirian Siliane Batista de Souza ${ }^{\mathrm{III}}$
}

\section{- NOTA -}

\section{RESUMO}

O presente relato descreve o caso de uma fêmea canina, adulta, sem raça definida, que havia parido há 45 dias e, posteriormente, apresentou ruptura uterina e vaginal com retroflexão e evisceração de bexiga, condição raramente observada em cadelas. O reposicionamento da vesícula urinária e a ovariosalpingohisterectomia (OSH) foram realizados por meio de abordagem cirúrgica, entretanto, o animal veio a óbito durante o segundo procedimento citado. Nesse caso acredita-se que as lesões no trato reprodutor provavelmente ocorreram durante o parto, sendo o óbito atribuído ao quadro de choque séptico.

Palavras-chave: retroflexão, bexiga, útero, ruptura vaginal, canina.

\section{ABSTRACT}

The current study describes a case of a female dog, adult, mixed breed, 45 days after delivery, which later showing uterine and vaginal rupture with bladder retroflexion and evisceration, condition that is rarely observed in dogs. The replacement of the bladder and ovariosalpingohisterectomy $(\mathrm{OSH})$ were performed by surgical approach, however the animal died during the second procedure. In this case, we believe that the damage in the reproductive tract probably occurred during labor and the death was attributed to septic shock.

Key words: retroflexion, bladder, uterus, vaginal rupture, dog.
O prolapso de vísceras pélvicas como útero, vagina, bexiga e segmentos intestinais pode ocorrer devido a alguns fatores, como a flacidez dos ligamentos pélvicos e o aumento da pressão abdominal resultante de trauma, parto e tenesmo (VICENTE, 1985; PETER, 1989). Após distocias ou traumas, podem ocorrer lacerações vaginais, permitindo a passagem da bexiga através da vagina (PRASSINOS et al., 2010).

A evisceração da bexiga através da vagina pode ser observada em todas as espécies, ocorrendo mais comumente em animais domésticos de grande porte no período pré ou pós-parto, sendo rara em animais de pequeno porte (TONIOLLO, 2004; PRASSINOS et al., 2010).

Essa enfermidade deve ser diferenciada do prolapso vaginal e uterino, dos tumores e hematomas vulvares ou vaginais, evisceração de demais órgãos através de lesões na vagina e eversão da bexiga. Esta última foi relatada somente em grandes animais que apresentam a uretra larga, permitindo a passagem da bexiga, expondo a mucosa vesical através da vagina (VICENTE, 1985; PETER, 1989).

O tratamento para retroflexão com evisceração da vesícula urinária consiste em limpeza com soluções não irritantes (solução fisiológica 0,9\%), punção e esvaziamento, seguidos da reintrodução do

\footnotetext{
'Residência em Cirurgia de Pequenos Animais, Universidade Estadual de Londrina (UEL), Rua Guararapes, 76, 86015-090, Londrina, PR, Brasil. E-mail: brunacoutinhovet@gmail.com. *Autor para correspondência.

"Programa de Pós-graduação em Medicina Veterinária (PPGMV), Centro de Ciências Rurais (CCR), Universidade Federal de Santa Maria (UFSM), Santa Maria, RS, Brasil.

"IIIepartamento de Clínicas de Pequenos Animais (DCPA), UEL, Londrina, PR, Brasil.
} 
órgão à cavidade abdominal através da ruptura vaginal e posterior síntese (DELCARLO et al., 1984). Em alguns casos, devido às alterações resultantes dos transtornos circulatórios, é necessária a realização de celiotomia mediana para tracionamento e reposicionamento da bexiga (PRASSINOS et al., 2010). O prognóstico apresenta-se favorável desde que o paciente seja atendido rapidamente e que não haja lesões extensas no órgão, tornando inviável sua preservação (VICENTE, 1985; TONIOLLO, 2003; TONIOLLO et al., 2004).

A ruptura uterina pode ser parcial ou total, ocorrendo com maior frequência em úteros aumentados de tamanho e desvitalizados, seja por uma gestação, por acúmulo de secreções, pela presença de tumores na luz do órgão, torção ou distocia. Durante a gestação, o útero pode romper-se por infecções graves, trauma externo ou interno e por causas iatrogênicas, como a manipulação obstétrica inadequada e o uso incorreto de fármacos, como ocitocina e prostaglandina $\mathrm{F}_{2 \alpha}$, que podem provocar a ruptura por estímulos de contração da musculatura uterina (NASCIMENTO, 2003; SORRIBAS, 2009; HUMM et al., 2010).

Alguns animais com lesões uterinas podem apresentar-se assintomáticos, principalmente os felinos, entretanto, essa é uma enfermidade grave e os sinais clínicos mais comumente observados são: apatia, secreção vulvar sanguinolenta, mucosas pálidas, desidratação, dor à palpação abdominal, choque hipovolêmico e morte (LUCAS etal., 2003; SORRIBAS, 2009).

O tratamento para rupturas uterinas consiste na síntese das lesões ou OSH, fazendo-se necessário, em alguns casos, anteriormente ao tratamento cirúrgico, a reconstituição da volemia do paciente por meio da administração de soluções hidroeletrolíticas, expansores de plasma ou sangue (SORRIBAS, 2009; HUMM et al., 2010). Por ser raramente observado, este trabalho teve como objetivo relatar um caso de retroflexão e evisceração de bexiga em cadela com lesões em trato reprodutor.

Uma canina, sem raça definida, adulta, de 20,5 quilos, foi atendida no setor de pronto socorro do Hospital Veterinário da Universidade Estadual de Londrina com histórico de apresentar, há três dias, um aumento de volume exteriorizado através da vulva, associado a um quadro de hematúria e disúria. O proprietário ainda relatou que, há aproximadamente 45 dias, a paciente havia parido sete filhotes de parto normal e, desde então, apresentava moderada prostração, polidipsia, hiporexia e fezes pastosas.

Ao exame clínico, a cadela apresentava temperatura $37,9^{\circ} \mathrm{C}$, mucosas levemente pálidas, tempo de preenchimento capilar maior que dois segundos, desidratação moderada, apatia, pulso fraco, baixo escore corporal, todas as mamas continham secreção láctea e a vulva encontrava-se edemaciada, apresentando uma estrutura arredondada exteriorizada através dela. À inspeção e palpação observou-se que se tratava da bexiga, a qual se apresentava moderadamente repleta, com a parede espessada, cheia de sujidades, congesta e com algumas áreas de necrose tecidual (Figura 1A). Esta se encontrava exposta através de uma lesão vaginal.

No atendimento clínico, foi realizada coleta de sangue para hemograma completo e perfil bioquímico. Foi realizada higienização do órgão com solução fisiológica $0.9 \%$, seguida de esvaziamento do conteúdo vesical por cistocentese, sendo drenados $340 \mathrm{ml}$ de urina com coloração vermelho amarronzada. Após o esvaziamento da vesícula urinária, tentou-se reintroduzir o órgão através da vulva, entretanto, não foi possível, devido ao edema presente nas estruturas acometidas (bexiga, vulva, vagina).

Os exames complementares demonstraram discreta anemia (volume globular $=34,3 \%$ ), trombocitopenia (150.000), número de leucócitos normais (13.880), entretanto, com desvio à esquerda (416,4 bastonetes), hipoglicemia $\left(46,5 \mathrm{mg} \mathrm{dL}^{-1}\right)$, hipoproteinemia $\left(3,3 \mathrm{~g} \mathrm{dL}^{-1}\right)$, hipoalbuminemia $\left(1,8 \mathrm{~d} \mathrm{dL}^{-1}\right)$ e os níveis de ureia e creatinina estavam aumentados (116,9 $\mathrm{mg} \mathrm{dL}^{-1}$ e $2,68 \mathrm{mg} \mathrm{dL}^{-1}$, respectivamente).

Como os exames clínicos e hematológicos sugeriam quadro de choque séptico, foi instituída na paciente fluidoterapia com solução fisiológica $0,9 \%$, suplementada com glicose, administração de antibiótico de largo espectro a base de cefazolina, na dose de $30 \mathrm{mg} \mathrm{kg}^{-1}$, por via intravenosa, e analgésicos a base de cloridrato de tramadol, na dose de $3 \mathrm{mg} \mathrm{kg}^{-1}$ pela via subcutânea. Em seguida, foi realizada celiotomia mediana ventral, para reposicionamento da bexiga em sua topografia original.

Durante o procedimento cirúrgico, observouse que o animal apresentava peritonite com acúmulo de líquido turvo de coloração amarelada e odor fétido em cavidade peritoneal. Além disso, na inspeção do trato reprodutor, detectou-se ruptura em face ventral de corpo e corno uterino direito e vagina com aproximadamente seis centímetros de comprimento, sem sangramento ativo ou presença de coágulos (Figura 1B).

Após limpeza da bexiga com solução fisiológica $0,9 \%$, realizou-se o seu reposicionamento, com a ajuda de um auxiliar, que reintroduziu o órgão através da vulva, de forma asséptica, enquanto o cirurgião tracionava-o para o interior da cavidade abdominal. Em seguida, foi avaliada a integridade do sistema urinário, o qual não apresentava rupturas. Procedeu-se à realização de OSH devido à lesão uterina, 


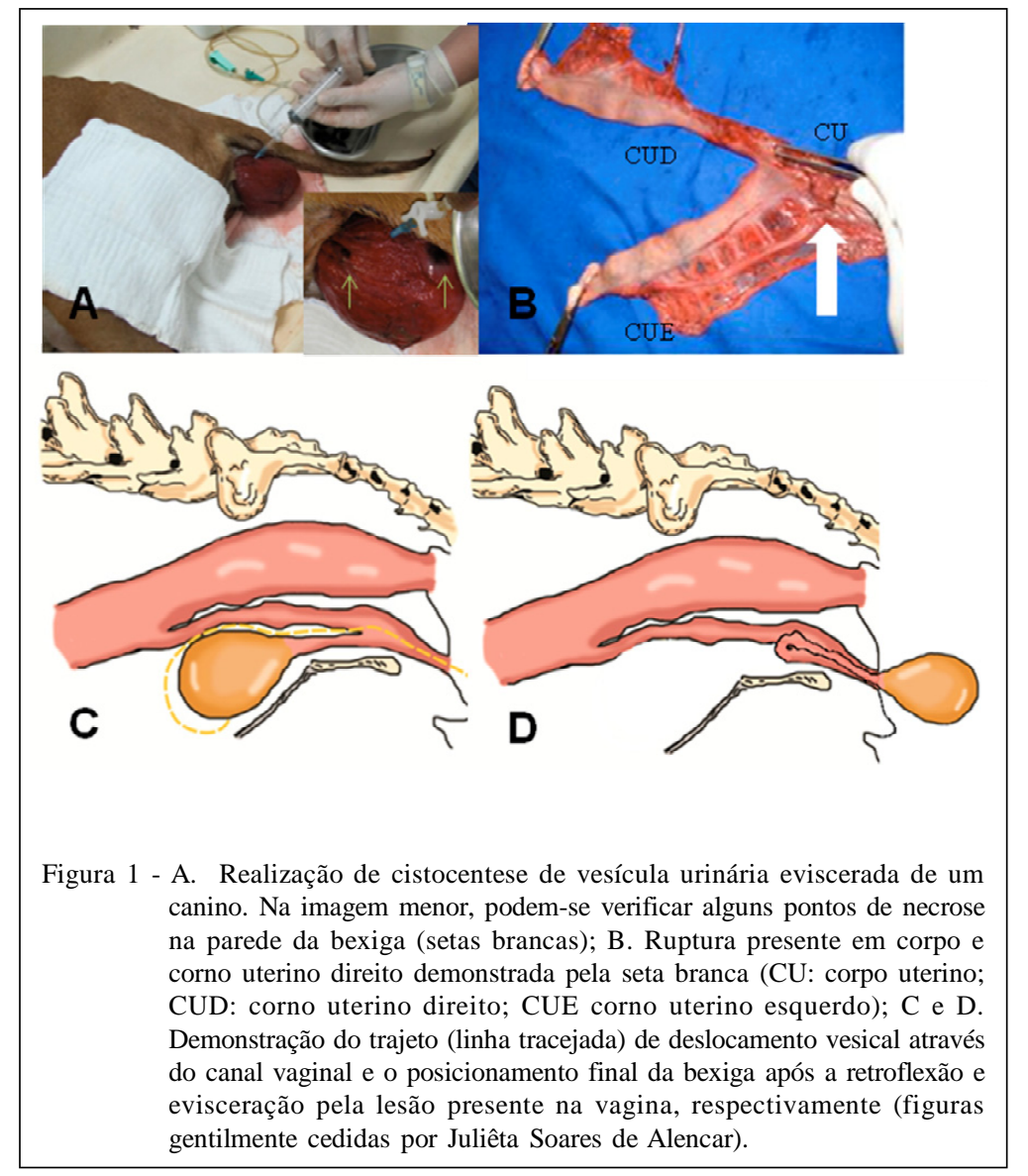

entretanto, durante esse procedimento a paciente apresentou duas paradas cardiorrespiratórias, vindo a óbito antes do término da cirurgia.

A ruptura da parede do trato genital é uma condição rara em animais de companhia e ocorre principalmente em casos de distocia (PRASSINOS et al., 2010). De acordo com a literatura, a evisceração de órgãos abdominais pode ocorrer quando há lesão vaginal (DEL CARLO et al., 1984), assim como observado no caso aqui relatado, no qual a fêmea apresentava tanto lesão uterina como vaginal, permitindo a saída da vesícula urinária de sua topografia normal.

HAYES (2004) relatou o caso de uma cadela com lesão uterina antiga, por provável trauma externo, porém, na época do acidente, o animal não apresentou os sinais que geralmente são observados nesses quadros. No presente caso, a paciente havia parido há 45 dias e, após o parto, apresentou somente discreta apatia e hiporexia. Acredita-se que as lesões no trato reprodutor tenham ocorrido no momento do parto, pois não foram observados indícios de lesão aguda no trato reprodutor.
Casos de peritonite resultantes tanto de ruptura uterina, como de contato visceral com o ambiente externo em quadro de ruptura vaginal já foram descritos (HUMM et al., 2010; PRASSINOS et al., 2010). Neste caso, a paciente apresentava ambas as alterações, sendo essas as prováveis causas da peritonite observada no animal.

O tratamento para evisceração é considerado de caráter emergencial e consiste na estabilização do paciente, administração de fluidos e antibióticos de largo espectro, preservação da víscera exposta, mantendo-a limpa e umedecida, seguida da correção cirúrgica o mais rápido possível (CROAK et al., 2004). Essas medidas foram realizadas no presente caso, entretanto, a bexiga da paciente havia eviscerado três dias antes do momento da consulta e já apresentava áreas de necrose, sendo o óbito do animal atribuído ao seu quadro clínico geral grave.

A retroflexão de bexiga com evisceração por ruptura de vagina é uma condição rara em cadelas, cujo sucesso no tratamento é multifatorial e a viabilidade da 
vesícula urinária está relacionada ao tempo que o órgão ficou exposto e às lesões existentes. No caso aqui relatado, a falta de acompanhamento adequado no período puerperal e a não realização do prontoatendimento, quando ocorreu a evisceração, resultaram no desenvolvimento do quadro de choque séptico e agravamento no estado geral da paciente, culminando com o óbito.

\section{REFERÊNCIAS}

CROAK, A.J. et al. Characteristics of patients with vaginal rupture and evisceration. Obstetrics \& Gynecology, v.103, n.3, p.572-576, 2004. Disponível em: <http://www.jstage. jst.go.jp/article/sanpunosinpo/60/3/224/_pdf >. Acesso em: 21 fev. 2012. doi: 10.1097/01.Aog.000011 5507.26155.45.

DEL CARLO, R.J. et al. Retroflexão e evisceração de bexiga em suíno, após parto. Descrição de um caso. Arquivo Brasileiro de Meddicina Veterinária e Zootecnia, v.36, n.2, p.167-172, 1984.

HAYES, G. Asymptomatic uterine rupture in a bitch. Veterinary Record, v.154, p.438-439, 2004. Disponível em: $<$ http://veterinaryrecord.bmj.com/content/154/14/ 438.citation>. Acesso em: 02 jan. 2012. doi: 10.1136/ vr.154.14.438.

HUMM, K.R. et al. Uterine rupture and septic peritonitis following dystocia and assisted delivery in Great Dane bitch. Journal of the American Animal Hospital Association, v.46, p.353-357, 2010 .

LUCAS, X. et al. Uterine rupture in a cat. Veterinary Record, v.152, p.301-302, 2003. Disponível em: <http:// veterinaryrecord.bmj.com/content/152/10/301.extract $>$. Acesso em: 13 nov. 2011. doi: 10.1136/vr.152.10.301.

NASCIMENTO, E.F.; SANTOS, R.L. Patologias do útero. In: Patologia da reprodução dos animais domésticos. 2.ed. Guanabara Koogan, 2003. Cap.5, p.45.

PETER, A.T. et al. Herniation of distal jejunum into the partially everted urinary bladder of a cow. Canadian Veterinary Journal, v.30, p.830-831, 1989. Disponível em: <http:// www.ncbi.nlm.nih.gov/pmc/articles/PMC1681295/>. Acesso em: 18 set. 2011

PRASSINOS, N.N. et al. Vaginal rupture and evisceration in a dog. Acta Veterinaria Hungarica, v.58, n.3, p.309-315, 2010. Disponível em: <http://www.akademiai.com/content/ v523142840916p53/>. Acesso em: 12 jan. 2012. doi: 10.1556/ AVet.58.2010.3.4.

SORRIBAS, C.E. Massa abdominal palpável e/ou dor abdominal. In: ____. Emergências e afecções freqüentes do aparelho reprodutor em cães. Curitiba: MedVet, 2009. Cap.3, p.40-41.

TONIOLLO, G.H.; VICENTE, W.R.R. Fisiopatologia do puerpério. In: Manual de obstetrícia veterinária. São Paulo: Varela, 2003. Cap.12, p.102.

TONIOLLO, G.H. et al. Retroflexão de bexiga. Relato de caso em Blastocerusdichotomus (Cervo-do-Pantanal). Brazilian Journal of Veterinary Research and Animal Science, v.41, n.2, p.137-139, 2004. Disponível em: 〈http://www.scielo.br/ scielo.php?script=sci_arttex\&lng=en $\& n r m=i s o>$. Acesso em: 26 out. 2011

VICENTE, W.R.R.; TONIOLLO, GH. Prolapso de bexiga em suíno (relato de caso). Ars veterinária, v.1, n.1, p.145-147, 1985. 